IJIET, e-ISSN 2548-8430, p-ISSN 2548-8422, Vol. 1, No. 2, July 2017

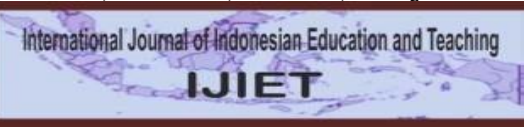

International Journal of Indonesian Education and Teaching http://e-journal.usd.ac.id/index.php/IJIET

Sanata Dharma University, Yogyakarta, Indonesia

\title{
FOSTERING LEARNING AUTONOMY THROUGH THE IMPLEMENTATION OF FLIPPED LEARNING IN LANGUAGE TEACHING MEDIA COURSE
}

\author{
Mega Wulandari \\ English Language Education Study Program \\ Sanata Dharma University \\ mega@usd.ac.id \\ https://doi.org/10.24071/ijiet.2017.010209
}

received 29 May 2017; revised 13 June 2017; accepted 3 July 2017

\begin{abstract}
Dealing with millennial generations, it is essential that educators adjust the educational paradigm in order to adapt to the needs of students in the digital age as it is today. This research studied about the implementation of flipped classroom learning model in Language Teaching Media (LTM) to foster fifth semester students' learning autonomy in English Teacher Education Study Program, Sanata Dharma University. Through the implementation of flipped classroom using Learning Management System (LMS), it is expected to model innovative teaching strategies, such as flipped classrooms, in an effort to prepare preservice teachers for 21 st century education. Findings from this research indicated positive perception towards flipped classroom in fostering learning autonomy in terms of planning, classroom engagement and self-evaluation.
\end{abstract}

Keywords: flipped classroom, Moodle, Language Teaching Media

\section{Introduction}

The integration of technology in higher education provides an opportunity to transform traditional pedagogy in order to achieve the needs of the millennial generation. Millennial are those born in 1982-2002 and make technology a part of their everyday lives (Wilson \& Gerber, 2008). In teachers training program at the university level, a learning model that focuses on the use of this technology can equip preservice teachers with the pedagogical skills and strategies they will need to address the next generation - the generation that will become their future students.

Preservice teachers should be introduced to innovative learning models that integrate traditional learning with technology. One of the learning models that offer novelty and pedagogical innovation is flipped learning or flipped classroom. In the flipped classroom, the presentation of the material is given not in the classroom, but outside the classroom by means of learning management system (LMS) platform or educational website. Learning materials in form of video, pdf files, presentation files, online quizzes or other forms of digital content are uploaded on LMS and accessible to students without time and space boundaries. Flipped learning exchanges a process that traditionally represents the portion of 
teacher teaching into a portion of student learning independently before face-toface meetings take place (Flipped Learning Network, 2013). With that concept, students can adjust to the learning ability of each individual to grasp better understanding of the content knowledge. The availability of material in form of video gives students the freedom to stop or repeat the material anytime in areas they still consider hard to understand. Then, when students attend the classroom meetings, students are expected to participate in the activities of implementing the material they have watched or read before (Tucker, 2012). This learning model not only provides an opportunity for students to have responsibility for their own learning, but also gives more time in the classroom to explore the materials more broadly and deeply.

The preservice teacher students were the target audience for this model as it was decided that they would benefit most from hands-on experience of the innovative teaching strategy. The students taking this course are in their third year of teachers training program and have either recently decided to be teachers. One of the most effective ways to teach preservice students how to engage theirstudents is by engaging them through their own coursework (Vaughan, 2014). It isessential not only to provide students with a rich experience in the teacher development program, but also to make university teachers in the faculty of teacher training remain aware of the changing nature of education and prepare students accordingly.

In response to that, Sanata Dharma University (USD) has made various attempts to continuously improve the quality of learning. Therefore, through the Center for Development and Learning Quality Assurance, USD develops Exelsa, which is an internet-based platform based on Moodle as a digital learning resource, for its academic community which can be accessed through http://exelsa2012.usd.ac.id/. Lecturers and students can establish synchronous or asynchronous computer-mediated communication through Exelsa. Lecturers can present teaching materials and tasks online, while students can easily access and review teaching materials through Exelsa independently. So, it is expected that they can self-regulate their own learning process and foster their autonomous learning skills.

Being an autonomous learner means the students have the capacity to manage their own learning process, started from choosing the most suitable learning method, selecting the media that can give them better understanding, and conducting self-evaluation method to measure whether the learning process meets the goals they have set previously. This way, learners are able to develop not only knowledge but also other skills like critical thinking, problem solving, and even personal skills such as responsibility, honesty, and integrity. Through the integration of technology, it is expected to produce autonomous learners that are able to plan, monitor, and evaluate their own learning process. The purpose of this study is to investigate how this learning model is implemented and perceived. The facts mentioned above raise awareness and necessity in conducting a research by utilizing Exelsa in the Language Teaching Media (LTM) course as the initial step to achieve what is aspired by Sanata Dharma University: shaping independent academic community who are capable of becoming agents of change in the future. 


\section{Theory}

Flipped Classroom is a learning model that reverses traditional methods, where materials are usually given in class and students do homework assignments. The Flipped Classroom concept includes active learning, student engagement, and podcasting (Vaughan, 2014). In the flipped classroom, the material is given in advance through the instructional videos that students must watch in their homes. In contrast, classroom learning sessions are used for group discussions and work on assignments (Flipped Learning Network, 2013).

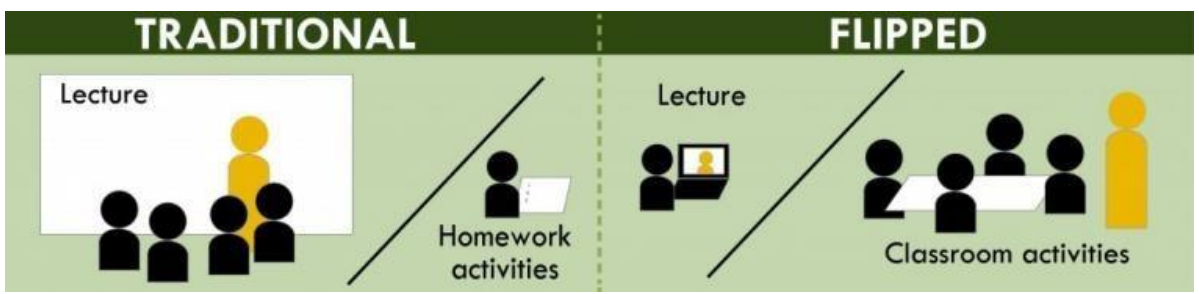

Figure 1. The difference between traditional classroom and flipped classroom

Several researches that examine the effect of flipped classroom on student achievement have been conducted. Benefits such as increased student engagement, increased feedback between teacher-students and among students, as well as the degree of student independence have been documented in several literatures (Goodwin \& Miller, 2013; Roehl, Reddy, \& Shannon, 2013;Sadhaghiani, 2012). Although the benefits have been widely studied, not many have applied to teacher training programs since most of the application of flipped classrooms is done in the field of science (Sadaghiani, 2012). Meanwhile, providing innovative and creative learning models should be the foundation of teacher training programs, because optimal learning is done by having a hands-on experience. This can be seen in Dale's Cone of Experience (Dale, 1946) which describes how learning process can affect the level of students' understanding. At Dale's Cone of Experience, the model of a real experience gets the largest share incontributing to a person's level of understanding.

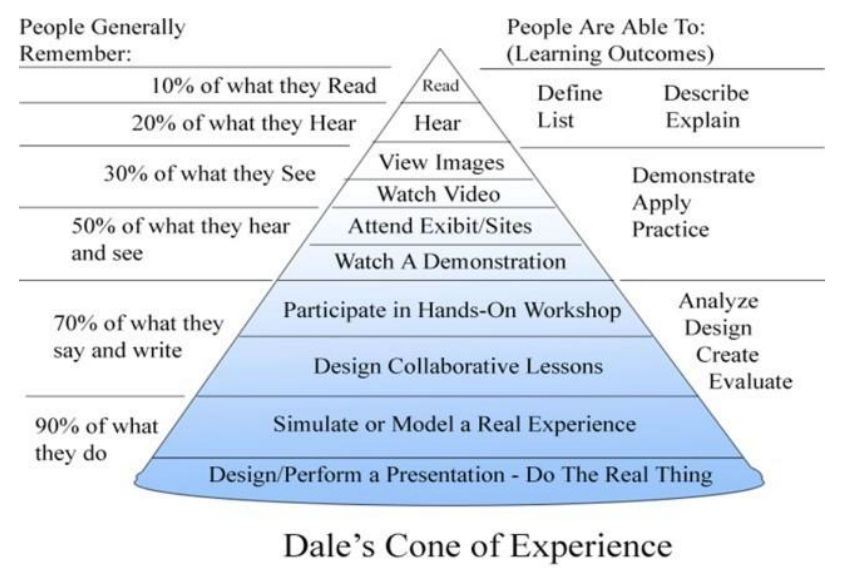

Figure 2. Dale's Cone of Experience 
However, despite having many advantages, flipped classroom requires careful preparation in order to run optimally. Flipping the classroom involves much more than adding technology and out-of-class video activities to your lessons; it requires both teachers and students to "flip" the way they fundamentally view education (Webb, Doman, Pusey, 2014). Teachers should certainly invest time to provide learning with interesting, quality, and comprehensible digital content. While students, on the other hand, should have access to a reliable internet connection and a high level of learning autonomy.

In the teacher training program, it is essential to encourage students to be autonomous. Before encouraging their future students to be autonomous learners, they have to become one themselves. Subsequently, they can be facilitator for their students, not to feed them knowledge but to help providing supportivelearning environment. As Thanasoulas (2000) said, this can be done by performing some activities such as asking them to write learning diaries where they can set and evaluate their goals, make portfolio where teachers can give feedbacks to motivate the students, encourage students to use technology to enrichtheir knowledge, and some activities that require students to discuss and perform critical thinking. If it is done continuously, the attitude of autonomous learner willbe eventually developed. The autonomous learning skill need to be trained, so that they can become individuals who always develop, improve, and renew theirknowledge throughout their lives.

Brookfield (2009) emphasizes that independent students take responsibility for their own learning processes cognitively, metacognitively, and affectively. Furthermore, Nunan (1996) reveals that independent learners refer to students who are self-motivated, responsible, and actively able to enrich themselves with any knowledge related to the learning process being undertaken. The ability to be responsible for the learning process is manifested in the student's ability to plan, monitor and evaluate him (Brookfield, 2009).

Departing from the definition of autonomous learning, it can be concluded that autonomous learning is the willingness of students to conduct learning activities that rest on the activities (planning, monitoring, evaluating) driven by the force within themselves in an effort to achieve goals that are considered valuable and useful. With the flipped classroom model, it is expected to encourageand train students who are preservice teachers to become independent learners.

\section{Method}

This investigation was a survey study set in Yogyakarta, Indonesia. English language classes at the university where the research was undertaken were held in the English Language Education Study Program (ELESP), a department within the Faculty of Education and Teachers Training. All enrolled students were required to take 4 year-long English language courses as part of their requirementsto gain an S.Pd. (BA in Education), so they were considered as preservice teachersor teacher candidates. This research employed questionnaire instrument to answer two problem formulations: 
1) What is the student's perception of the implementation of flipped learning model?

2) To what extent flipped learning is able to foster students' autonomous learning skills?

The questionnaire was developed using Google Form which consists of 2 parts, that is close-ended and open-ended. The questionnaire was embedded on Exelsa. The survey was conducted at the end of the 2016/2017 fall semester to 50 respondents from 2 Language Teaching Media (LTM) classes (Class A and E) in the Sanata Dharma University. Respondents were students of class of 2012-2014, aged 19-29 years and consist of $76 \%$ women and $24 \%$ men. In addition to the survey, discussion forum notes, reflections, and observations were reviewed and coded according to the categories of planning, engagement and self-evaluation. This method was applied to increase validity of the data and avoid bias (Maxwell, 2005).

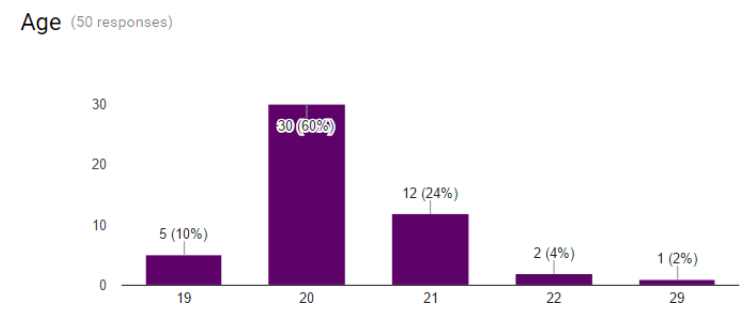

Figure 3. Demographic chart of the research participants

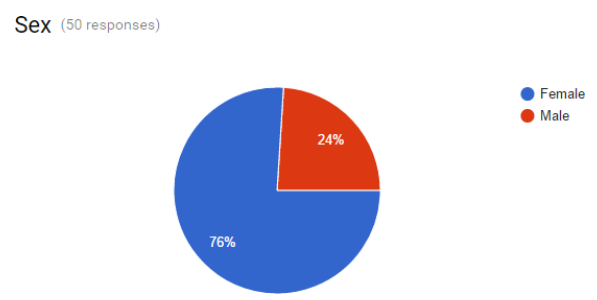

Figure 4. Demographic data of research participants

The final report describes the results of a numerical survey (from closeended questions) and descriptive (from open-ended questions) to flipped learning implementation in LTM course and students' perceptions of flipped classroom learning model.

\section{Findings and Discussion}

The survey results show positive perceptions of students that can be seen from how students plan lessons, engage in the classroom, and evaluate learning independently.

Autonomous learning starts from the planning stage where students prepare themselves before they enter into the learning process. According to Grieve 
(2003) autonomous learning is a personal attribute, the psychological readiness of a person in controlling or responsible in the learning process. Thus, a person who is independently ready can identify his needs and the purpose of why he should learn something. In the learning autonomy, the individual learns about his own interests, makes plans and takes action. They also think about the processes they will undergo, solutions to problems and strategies for developing their abilities.

The researcher, who in this case also acts as a teacher, uploads instructional materials in form of videos, assigned readings, individual quizzes and presentations to be previewed by students before the actual face-to-face meetings take place. This strategy is applied so that students attend the class with their prepared minds and ready to apply the knowledge they have gained from the uploaded materials. This meant that every chapter covered for LTM course would be "at-home" activity and every class that students attended face-to-face would be an active learning experience. Therefore, discussion and collaboration on projects would take up the bulk of classroom time. By flipping the entire semester, the model would truly be executed and the students would have a rich lesson in experimenting with innovative teaching. The following is the result of the questionnaire on planning stage.

Planning

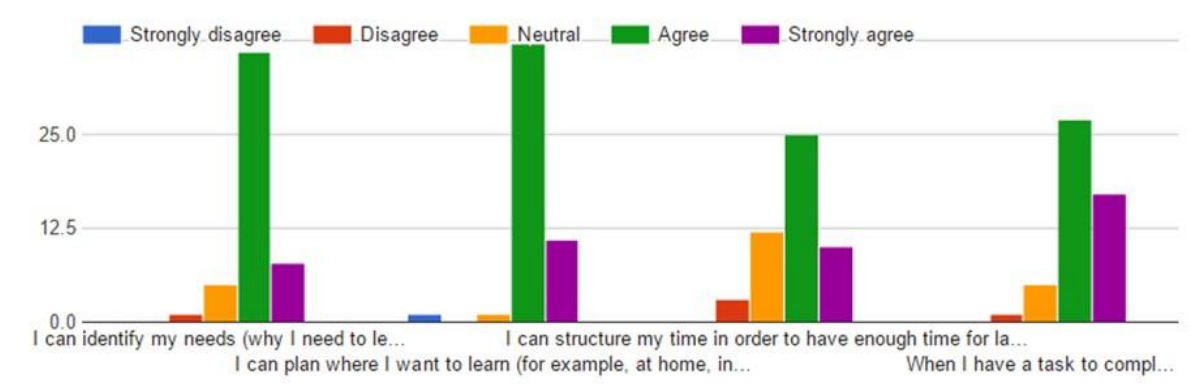

Figure 5. The result of the questionnaire in the planning stage

The bar chart above shows that the majority of respondents (16\% strongly agree and $72 \%$ agree) stated that with flipped classroom model, they can identify their learning needs, they can set the place and time to complete a task, and they can preview the materials. The Moodle-based materials help the teacher to provide students with sufficient information on the importance of learning amaterial to be taught. The information provided by the teacher is accessible to students and it can encourage them to make sense of what they will learn. This is supported by the results of their open-ended questionnaire:

S135- "[...] I try to read the material before the class begins, and that really helps me to understand the material better."

S127-"Flipped classroom helps me to learn individually before I start learning in the class. I can read several references about certain topics. It helps me to prepare and have background knowledge first." 
Nevertheless, there are still a small number of students (10\% neutral, and $2 \%$ disagree) who say that flipped classroom has no effect on their learning plans. It can be caused by some factors such as the choice of learning methods or internet facilities.

S132- "I don't have internet connection at home. I usually come to class earlier to read or watch the videos posted by the teacher before the class started."

S125- "I prefer listening to my lecturer rather than reading a material posted on Exelsa. Maybe that's just my choice."

In addition to students' awareness of learning needs, autonomous learning can also be seen from how students regulate themselves in terms of time andplace. With flipped classroom, learning materials can be accessed without timeand space restrictions. Students can access the material uploaded into Exelsa from anywhere as long as they are connected to the internet network, such as in the student hall, Self-Access Center, or in their respective homes. From the data above, $96 \%$ of respondents agreed that they can structure their time and place of study independently. Meanwhile, only 4\% said they disagreed. It shows that flipped learning provides flexibility for students to be able to access learning materials at the time and place that is most convenient for them. This can be seen from the student comments below:

S146- "[...] using Exelsa is really helpful for us because we can be independent learners anywhere and anytime. We know what to do when the lecturer gave us an assignment. I can review all the material from my boarding house or SAC."

S003-"This course gave me an easy access to recall the last material that we have learned by using Exelsa. So that, when I want to learn more about it outside the class, I can open it easily."

Autonomous learning can also be seen from how they will complete the tasks. An autonomous learner can plan goals, design the right time and place to complete a task, and plan the steps to be undertaken. There are $88 \%$ of respondents said they can do planning for task completion. In the LTM course, there are several projects that they need to complete either individually or in groups. Projects cover the creation of media, both technical and conventional. Once, they have completed a media, the next stage is to do a teaching simulation. The simulation is essential to evaluate whether the media they have created can beeffectively implemented in the classroom. Some videos and journal articles are uploaded into Exelsa to guide them in the task completion, and all students can do and get it done well. 


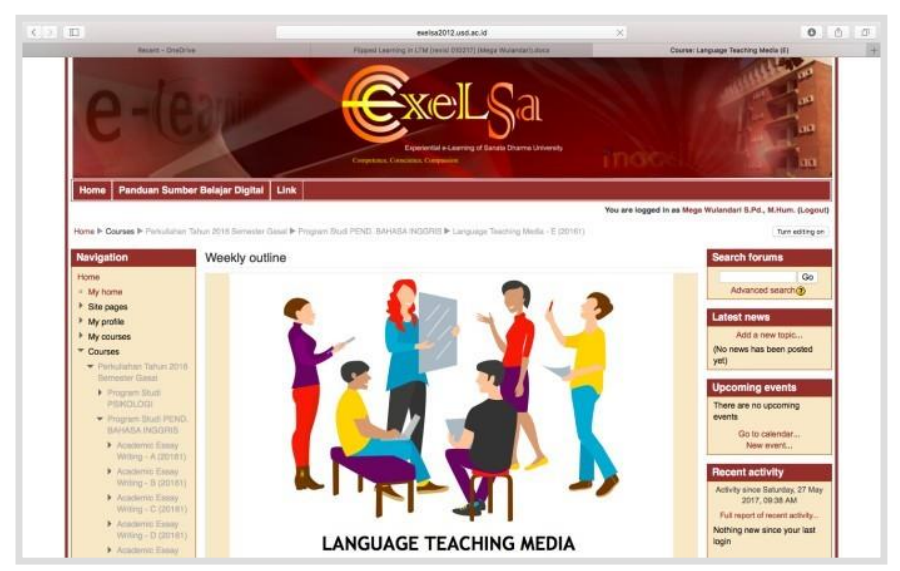

Figure 6. Screenshot of LTM Moodle-based material on Exelsa

The actual challenge of a teacher was to engage students in authentic and meaningful activities. Teachers' role includes providing activities that deepen their understanding of both content and pedagogy knowledge, such as discussions, presentations, and teaching simulations. Using flipped learning, in-class activities can also provide a space for teachers to clarify misconceptions encountered by students in "at-home" activities. Here is the result of the survey about student engagement.

\section{Learning Engagement}

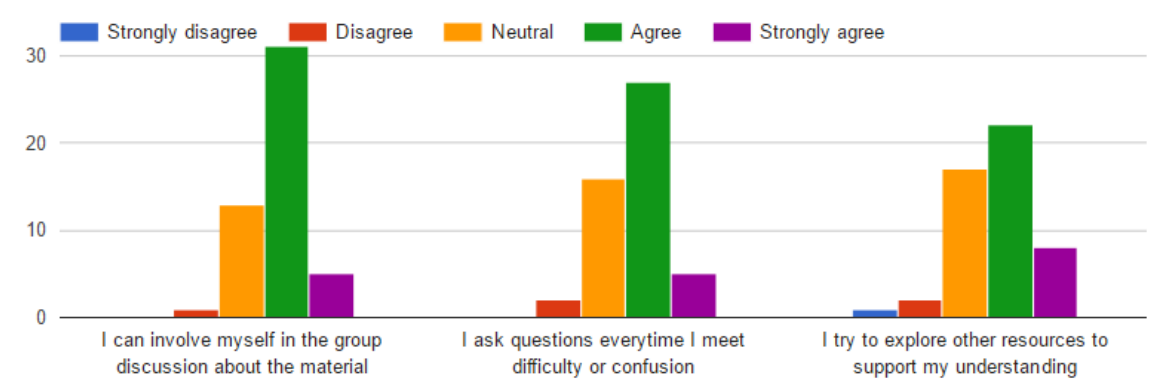

Figure 7. The chart of students' engagement in class

On the chart above, it was shown that $72 \%$ of students stated that they were able to be actively involved in group discussions. It can be said that a majority of students felt that the flipped classrooms were helpful, and they agreed that the additional time spent in class working on problem-solving activities greatly enhanced their understanding of the concepts, for instance when they learned about presentation media. The teacher gave students some choices of presentation media, such as Microsoft PowerPoint and Prezi. After studying the two, students then come to the classroom by preparing arguments for their choice. They explain the advantages and disadvantages of each media and determine the best. The discussion was very well executed, since every student had understood the concept of each media by reviewing some references before coming to class. This is a major advantage of using the flipped classroom.

Through the process of self-paced learning they had done prior to class, misconceptions were sometimes inevitable. Teachers should emphasize that 
asking questions in class was essential in the learning process to avoid misconceptions. From the chart, it was displayed that $64 \%$ of participants asked questions when encountering difficulties in their understanding of the materials. Based on the observation, the questions were expressed in class discussion forums as well as in group discussion forums. In the flipped classroom, they asked more questions about what was "allowed and not allowed". This activity illustrates the increased depth in the outcome occurred when students understand and reflect on the content prior to class.

Besides aiming to provide opportunities for students to understand teaching materials prior to face-to-face meetings, the flipped classroom also aims to allow more time to explore broader references to the varied of language teaching media. In the course, students were expected to know myriad choices of language teaching media. In one in-class meeting, the teacher cannot explain all types and functions of the teaching media, instead expecting students to explore by themselves. Based on the data, $60 \%$ of students explore other references outside the class. For example when the students were assigned to create an explainer video, it can be created using different types of applications such as Windows Movie Maker, Powtoon, or Stopmotion. They will discuss their choice with their teammates in order to get their project done.

S127- "[...] When we are assigned to make an explainer video, I try to browse software mastery lessons on YouTube. I am very enthusiastic in producing media in this class."

S114- "[...] We had a problem when creating an explainer video. We couldn't make the voiceover sounds perfectly. So, we browsed how to edit and produce perfect voiceover for our video from YouTube videos. We're very happy because we finally made it!"

As explained above, the students searched for more information through YouTube videos to solve problems they encountered in the process of completing certain project. It sharpened the students' critical and creative thinking skills they might need as future teachers. It will also increase their digital literacy skill, because in the attempts of finding the best references, they would try to find the most reliable sources.

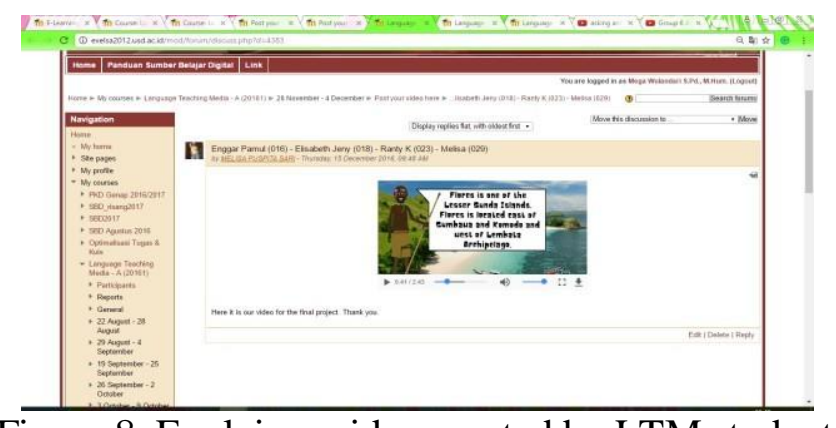

Figure 8. Explainer video created by LTM students 
Another essential aspect in the coursework is evaluation. Evaluation is one of the important components and stages that must be taken by students to know the effectiveness of the learning they have been through. Essentially, evaluation is a systematic and continuous process to determine the quality (value and meaning) of the learning process. Self-evaluation can be done in-class or out-class. For example, after watching the videos, students were also given different opportunities to show that they understood the content of the video either by responding to the video with an oral or written comment, creating their own video response, participating in an Exelsa forum discussion on the topic, or by answering questions on a handout or online quiz. The survey showed that flipped classroom, which was presented in the Moodle-based platform called Exelsa, gavethem opportunity to be autonomous learners by performing self-evaluation. The following chart is the result of the survey.

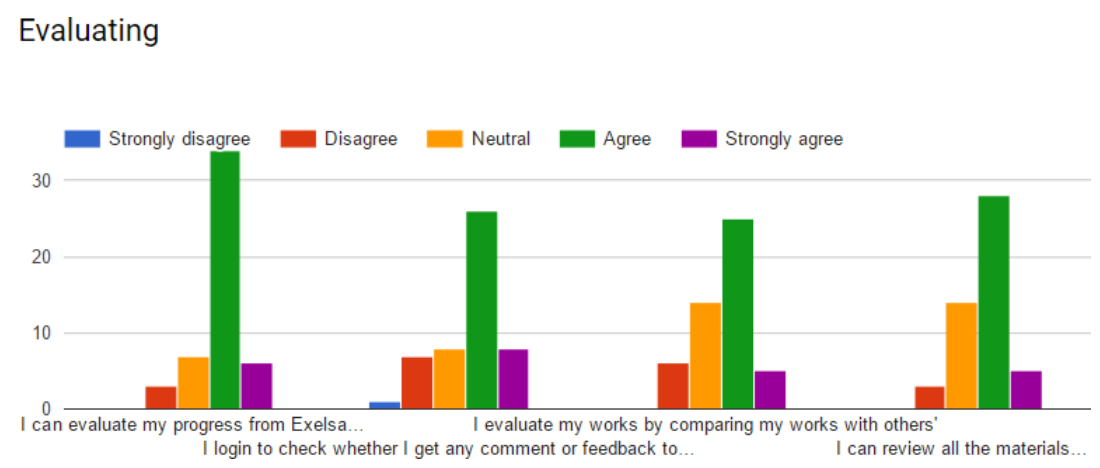

Figure 9. The chart of self-evaluation

Evaluation can be done by monitoring comments / feedback given on the post task, and also by comparing with the work of others. From the bar chart above, it shows that $80 \%$ of students regularly monitor the results of their scores obtained through the scoring record feature on Exelsa. 68\% of respondents accessed Exelsa to see if there were any comments or feedbacks they received for the work they uploaded on Exelsa. In additions, $60 \%$ of respondents said they compared the results of their classmates' postings to evaluate whether they had performed to achieve the desired results. Furthermore, $66 \%$ of respondents also read feedbacks on their classmates' products to see whether they were in accordance with the criteria specified. By learning from others, they can gain more meaningful knowledge and try to avoid pitfalls on the next project. Despite this, some suggestions were also given by the students related to feature of Exelsa.

S011-“I personally think that Exelsa is already decent enough for us to support our learning. However, it would be great if there is a kind of mobile application that we can install. So, we can get direct notification when somebody's giving us comments on our postings."

S025-"The communication between the lecturers and the students will be better if Exelsa has online chatting. So, when students wanted to ask something, we can directly reach our lecturer." 
S021-“[...]This course also fosters my independent learning through selfevaluation and also by comparing my work with my classmates' works. It makes me develop myself much because I have to find my own learning style that suits me best."

By conducting independent evaluation, students are expected to be able to boost their motivation to complete tasks more optimally and also develop themselves professionally as future teachers. By being autonomous learners who set their own goals, they can also explore things as they desire, because they also develop their own curiosity and eagerness to learn. Moreover, they can manage the most suitable learning method or media for them so their learning will be more effective.

\section{Conclusions}

The flipped classroom model constructed on the Exelsa platform has contributed to learning process in the Language Teaching Media course especially in fostering their autonomous learning skill. That includes instructional preparation, active learning engagement in the classroom, as well as the opportunity to evaluate independently. In additions, the flipped classroom learning model can train students' ability to be independent so they can be individuals who always develop, improve, and renew their knowledge throughout their lives.

Though findings from this research indicated positive perception towards flipped classroom in fostering learning autonomy in the coursework in terms of planning, classroom engagement and self-evaluation, several drawbacks from the research were also noted. The survey in this course did not serve as sufficient evidence to detail students' attitudes towards the flipped model in the EFL context. The researchers of this study suggest carefully defining the measurement of the data, and putting these constructs into definite SPSS measurement in order to ensure validity. The survey results presented in this study were not analyzed for such factors, which would have otherwise increased the reliability of the survey results.

\section{References}

Assessment \& Teaching of $21^{\text {st }}$ Century Skills (ATC21S). (2012). $21^{\text {st }}$ century skills. Retrieved from http://www.atc21s.org/

Brookfield, S. D. (2009). Self-directed learning. In International handbook of education for the changing world of work (pp. 2615-2627). Springer: Netherlands

Flipped Learning Network. (2013). Flippedlearning.org by Schoolwires. Retrieved from http://flippedlearning.org/site/default.aspx?PageID =1.

Goodwin, B \& Miller, K. (2013). Evidence on flipped classrooms is still coming in. Educational Leadership, 70(6), 78-80.

Grieves, J. (2003). Strategic human resource development. Thousand Oaks, CA: Sage. 
Maxwell, J. A. (2005). Qualitative research design: An interactive approach. Thousand Oaks, CA: Sage Publications, Inc.

Nunan, D. (1996). Towards autonomous learning: Some theoretical, empirical and practical issues. Taking Control: Autonomy in Language Learning, 13-26.

Roehl, A., Reddy, A. L. \& Shannon, G. J. (2013). The flipped classroom: An opportunity to engage millennial students through active learning strategies. Journal of Family \& Consumer Science, 105(2), 44-49.

Sadaghiani, H. R. (2012). Online pre lectures: An alternative to textbook reading assignments. The Physics Teacher, 50(5), 301-303.

Tucker, B. (2012). The flipped classroom. Education Next, 12(1), 82-83.

Vaughan, M. (2014). Flipping the learning: An investigation into the use of the flipped classroom model in an introductory teaching course. Education Research and Perspectives International Journal, 41, 25-41

Webb, M., Doman, E. \& Pusey, K. (2014). Flipping a Chinese university EFL course: What students and teachers think of the model. The Journal of Asia TEFL, 11(4), 53-87

Wilson, M. \& Gerber, L. E. (2008). How generational theory can improve teaching: Strategies for working with the 'millenials.' Currents in Teaching and Learning, 1(1), 29-44. 